\title{
Parks are Critical Urban Infrastructure: Perception and Use of Urban Green Spaces in NYC During COVID-19
}

\author{
Bianca Lopez, Christopher Kennedy, Timon McPhearson \\ Urban Systems Lab, The New School, 79 Fifth Avenue, 16th FI., New York, NY, 10003, USA
}

\begin{abstract}
Urban green spaces provide a range of environmental and health benefits, which may become even more critical during times of crisis such as the current COVID-19 pandemic. However, with a radical shift in mobility, additional concerns over safety, and access temporarily restricted during the implementation of social distancing policies, the experience and use of urban green spaces may be reduced. This is particularly concerning for densely populated cities like New York, considered the first U.S. epicenter or vanguard of the outbreak. To better understand the impact of COVID-19 on the perception and use of urban green spaces, we conducted a social survey during the early months of the Covid-19 pandemic in New York City (May 13 - June 15, 2020). The results of the survey show respondents continued to use urban green spaces during the pandemic and consider them to be more important for mental and physical health than before the pandemic began. However, the study revealed a pattern of concerns residents have about green space accessibility and safety, and found key differences between the concerns and needs of different populations, suggesting a crucial role for inclusive decision-making, support for additional management strategies, and urban ecosystem governance that reflect the differential values, needs and concerns of communities across the City. As urban centers face looming budget cuts and reduced capacity, this study provides some empirical evidence to illustrate the value of urban green spaces as critical urban infrastructure, and may have implications for funding, policy, and management, of urban green spaces in NYC, with potential applications to other cities, particularly during times of crisis.
\end{abstract}

\section{Keywords}

Urban green space, COVID-19, urban parks, open space, urban infrastructure, equity

\section{Introduction}

Urban parks, natural areas and other types of open spaces (e.g. gardens, yards, rooftops, plazas; hereafter referred to as "urban green spaces"), provide many environmental and health benefits, including shade and cooler temperatures (Heidt and Neef, 2008; ShashuaBar and Hoffman 2000), opportunities for recreation and exercise (Lee, Jordan, \& Horsley, 2015; Maas et al 2006), improved mood (Bratman et al 2015), and decreased anxiety and stress (Bratman et al 2019) among others. Opportunities for city dwellers to receive mental and physical health benefits from urban green spaces may become even more critical during times of crisis such as the current novel coronavirus (COVID-19) pandemic, as residents face heightened health-related and economic stress, isolation, and limited mobility during the 
implementation of social distancing policies (Brooks et al 2020). However, with decreased operational capacity, temporarily restricted access, and concerns over safety and overcrowding, the use of urban green spaces may shift or be reduced during the pandemic. This presents a unique challenge to city planners and park officials to ensure urban green space is accessible, safe and well-maintained, while also meeting the evolving needs of residents based on their experience, and the perceived access and importance during an extreme event.

Access to urban green spaces is not distributed equally in many cities, and is often considered an environmental justice issue (Rigolon 2016; Weiss et al 2011). Miyake et al. (2010) points out that while access to green spaces in New York City may appear equitable, higher rates of White residents live near large parks with a higher level of desired features. Additionally, the use of urban green spaces depends on more than just who is within physical proximity to parks, but what amenities those spaces provide, how well they match the needs of the community, and who feels safe and welcome to use the park (Auyeung et al 2016; Lo and Jim 2012). In a study analyzing NYC park usage through social media data, Hamstead et al. (2018) for instance found the key determinants of visitation are linked to park facilities, access to public transportation, the size of the park, and socio-demographics of the neighborhood. They found park visitation interestingly decreases with green space based on the proportion of minority communities who use them.

Although research is still emerging on urban green space use during the pandemic, a number of media reports and some studies have supported anecdotal evidence of increased park visitation as well as a shift in their perceived importance during COVID-19 (Fisher and Grima 2020; Venter et al 2020; Samuelsson et al 2020; Goldstein \& Kilgannon, 2020; Melendez 2020). However, what is less known is the shifting concerns residents have about urban green spaces, how they are being utilized differently, the change in perceived access, and what features have been identified as particularly desirable or useful across different social groups and demographics. As urban centers make difficult decisions about how to allocate limited resources and funding, these insights may play a key role in informing planning and park design for building resilience to current and future extreme events.

To better understand some of these intersecting issues, we deployed an online survey to NYC residents between May 13 and June 15, 2020, to assess resident's use and perceptions of urban green spaces in NYC. In this study, we analyze survey responses to address the following questions:

1. What concerns do people have about visiting urban green spaces during the pandemic?

2. How often are people using urban green spaces during the pandemic and how has their use of parks changed since the start of the pandemic?

3. Do people consider urban green spaces to be important for their physical and/or mental health, and have these perceptions changed since the start of the pandemic?

4. What features do people identify as important for urban green spaces to provide, and do they feel that urban green spaces are providing those features during the pandemic?

The analysis provided here examines differences in responses related to these questions across gender, race/ethnicity, and borough to identify inequities and differences in needs across demographics and geographies. The results of this study have implications for funding, policy, 
and management, of urban green spaces in NYC, with potential applications to other cities, particularly during times of crisis.

\section{Methods}

\section{Study site}

New York City is the largest city in the United States with approximately 8.4 million people according to the 2018 American Community Survey (U.S. Census Bureau 2020). The New York City Department of Parks and Recreation (NYC Parks) are the stewards of more than 1,700 parks, 1,000 playgrounds, 650,000 street trees, and 2 million park trees. NYC also contains over 12,000 acres of natural areas including the Jamaica Bay Wildlife Refuge, and 520 miles of coastlines and 8 public beaches (NYC Parks 2020). There are approximately 12,600 acres of public or "passive" open space (1.5 acres per 1,000 residents) such as plazas and esplanades within the city limits (Harnik 2016). In New York State, the first confirmed case of the SARSCoV-2 coronavirus, COVID-19, emerged on March 1, 2020 and soon spread to NYC through community transmission. With nearly $\sim 6 \%$ of national confirmed cases, and $\sim 16 \%$ of deaths, NYC has been described by scientists as the first U.S. epicenter or vanguard of the outbreak, prompting a shelter-in-place mandate (PAUSE) in addition to social distancing policies that include restricted access or temporary closure of public open spaces, parks, beaches, and other natural areas (New York State Department of Health and Mental Hygiene, 2020; Angel et al 2020). New York City's "PAUSE" policy has led to a large majority of residents being confined to their homes for most days, an interruption of worker commute, and induced a radical shift in the locations and demand for services including energy, transit, and green spaces. 


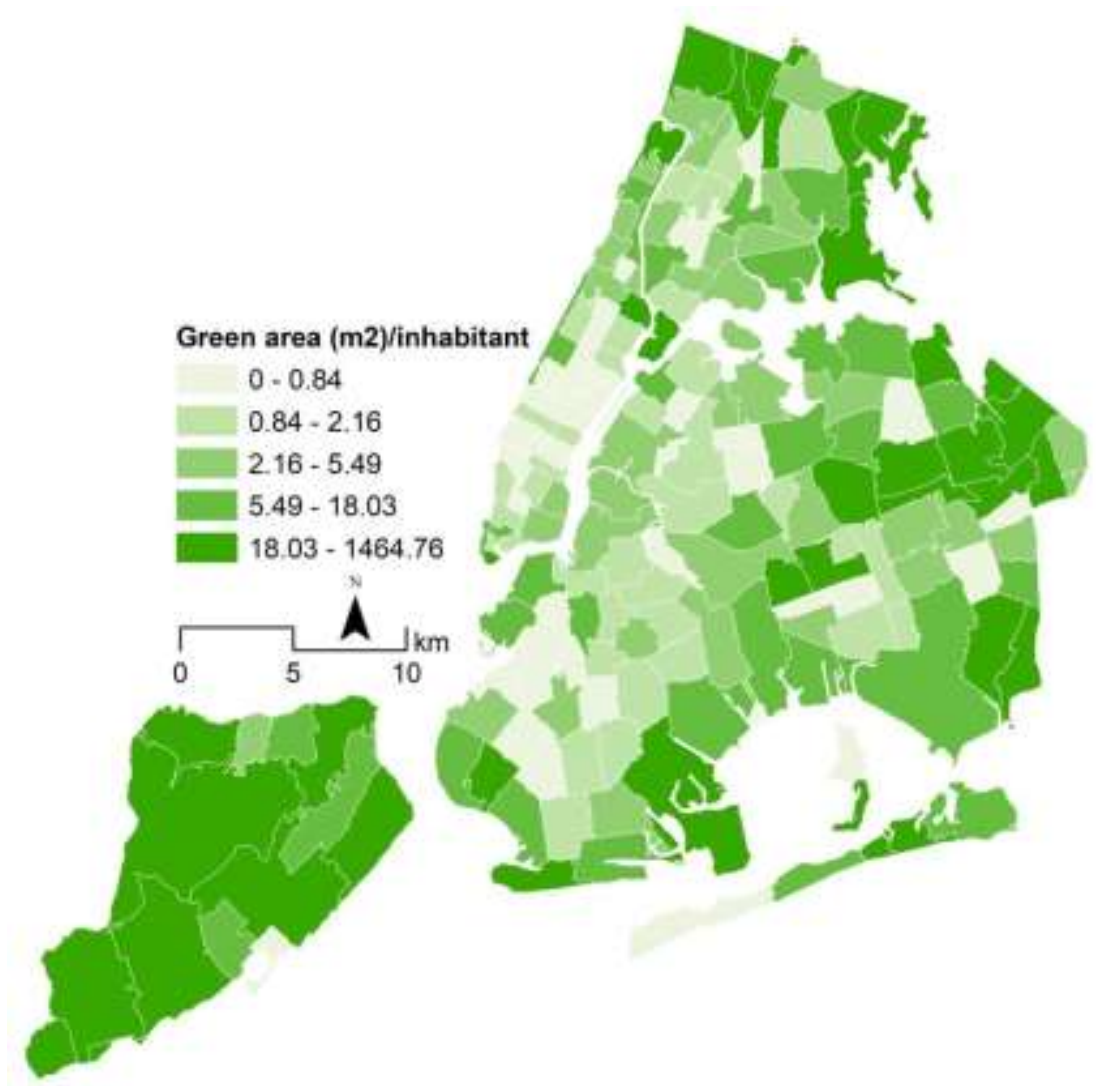

Figure 1. Urban green space area (m2) per NYC inhabitant.

\section{Survey Design}

We developed two surveys: a national survey designed to sample general populations (over the age of 18) in urban centers throughout the U.S., and the other for residents currently living in NYC. The NYC survey was co-developed with local partners, the New York State Health Foundation, The Nature Conservancy of New York, and Building Healthy Communities program with additional questions focused on the use of NYC Housing Authority (NYCHA) open spaces. An online instrument was developed for both surveys consisting of six sections of questions aimed at understanding how people are using urban green spaces during the COVID19 pandemic, how important people perceive urban green spaces to be for their health, and whether exposure to urban green spaces is affecting people's mental health during this time. In the survey we describe "urban parks and open spaces" as any public spaces with natural or managed vegetation, including parks, greenways, public gardens, and accessible wetlands, forest, prairies, and beaches within a close proximity to an urban center in the United States.

In the first section the survey asks questions about how often participants are going outside and what types of urban green spaces they perceive they have access to. The second section asks questions about participants' use of urban green spaces. These questions included: 1) how often participants have visited urban green spaces in the last week, 2) how they travel to urban green spaces they visit most often and how long it takes to get there, 3) whether or not they interacted with other people the last time they visited a park or open space, 4) how their last visit to a park or open space affected their mood and stress level, respectively, and 5) what concerns they have with visiting urban green spaces. The first question in Section 2 
asks which nature-related activities survey-takers participate in and, for each activity they select, whether they increased, decreased, began, or ended their participation in this activity during the COVID-19 crisis. Some other questions related to park and open space visits in this section (travel method and time, length of visit) were only shown to participants who selected that they participated in visiting parks and open space.

The third section of the survey asks participants to assess whether they have experienced feelings related to four aspects of their mental health (felt unhappy or depressed, lost sleep due to worry, been able to concentrate, been able to enjoy everyday activities) more or less in the last few weeks compared to "usual" (options: Much less than usual, Somewhat less than usual, The same as usual, Somewhat more than usual, Much more than usual) (adapted from White et al. 2013). In the following section participants are asked to rank, on a scale of 1 to 5, how important they think parks and open space are to their mental and physical health, respectively, and how important they thought parks and open space were for their mental and physical health before the COVID-19 crisis.

The fifth section asks questions about COVID-19 related stressors that may affect participants mental health, including: 1) where participants are currently living (options: In my primary home, In my secondary home or vacation home, In a relative's or friend's home, Other), 2) how many people are living in their household, how their income has shifted during the COVID-19 crisis (options: It has been extremely reduced, It has been moderately reduced, It has stayed constant, It has increased, Not applicable), and 3) whether they perceive themselves or anyone in their household to be at risk of severe health impacts from COVID-19. A final section collects basic demographic questions, including age, gender, race, ethnicity, household income, and zip code.

\section{Survey distribution}

We recruited survey participants using a combination of a convenience sample and snowball approach. We targeted several large, national networks who work with urban green spaces or communities to distribute the survey and share on social media. To design the survey and recruit participants in NYC, we worked with partners at The New York State Health Foundation, Building Healthy Communities NYC, and The Nature Conservancy New York.

\section{Data analysis}

We filtered responses for analysis to those that had completed at least $70 \%$ of the survey questions to cover the questions addressed in this study. We used generalized linear models to examine differences in survey responses across groups, focusing on gender (female, male, and nonbinary), NYC borough (Manhattan, Bronx, Queens, Brooklyn, and Staten Island), and coarse race and ethnicity categories (Asian, Black, Latinx, and White). Because respondents were able to select multiple racial identities and answered a separate question about Latinx/Hispanic identity, race/ethnicity categories were not considered to be mutually exclusive and were coded as separate variables. We used the "polr" function in the "MASS" package in R (Venables et al. 2002) to fit ordinal regressions for responses with ordered categories (i.e. travel time to most visited urban green space; number of visits to an urban green space in the past week; changes 
in urban green space visitation during the pandemic; perceived importance of urban green spaces for health). We used the "glm" function using the "family = binomial" argument to fit logit regressions predicting whether or not respondents selected each response for questions about concerns about, perceived access to, and important features of urban green spaces. To determine whether respondents' most visited parks provide the features they deem important, we calculated the proportion of features that each respondent selected as important that they also stated that their most visited urban green space provides. We analyzed differences in this proportion across gender, race/ethnicity, and borough using the "glm" function (family = "binomial") as with the responses about individual features.

We used linear regression with the "Im" function to examine the relationship between perceived access to public parks and the availability of green space at the zip code level. Data on green space came from the NYC Open Data portal (Figure 1), which provides a basemap polygon layer containing open space features, such as parks, courts, tracks, and cemeteries. All analyses were performed in R (R Core Team 2019).

\section{Results}

\section{Survey respondents}

In total, 1372 people took the NYC survey, and 1145 people completed over $70 \%$ of the survey questions used for this analysis. Of these, over $70 \%$ identified as female and $23 \%$ as male, with $\sim 2 \%$ identifying as nonbinary. Over $75 \%$ of respondents identified as white ( $72 \%$ as white only), $8 \%$ as Black, $7 \%$ as Asian, and $1 \%$ as American Indian, Native Hawaiian, or Pacific Islander. About $10 \%$ of respondents identified as Latinx. Nearly half of respondents (45\%) were in their twenties and thirties, and another $40 \%$ of respondents were $40-64$ years old. The largest household income classes represented in the data were $\$ 100,000-\$ 149,999$ (20\%) and over $\$ 200,000$ (17\%). Almost half of respondents (45\%) had completed a master's degree as their highest level of education, and another $31 \%$ had completed a bachelor's degree. Most responses came from Brooklyn (44\%) and Manhattan (32\%), with fewer from Queens (12\%), the Bronx (6\%) and Staten Island (1\%) and 5\% of respondents choosing not to provide information on their home borough. Over $85 \%$ of respondents stated that they use urban green spaces.

\section{Concerns about urban green spaces}

The most common concerns about visiting urban green spaces selected by respondents were that "People are not practicing social distancing" (59\%) and that parks were "Too crowded" $(57 \%)$. Additionally, $12 \%$ percent of respondents selected that they were concerned about "Too much police presence", $11 \%$ were concerned about "Not enough park staff", and $8 \%$ selected "I do not have easy access" to an urban green space. Thirteen percent of respondents stated that "It does not feel safe" to visit an urban green space, and 36 respondents wrote in additional concerns about safety. These included some concerns that were included in the previous question, such as a lack of cleanliness (i.e. excess garbage in parks), lack of adequate lighting, 
and crowded conditions or a lack of social distancing in parks (e.g. "I don't feel comfortable running in Prospect Park because it's too crowded."). Additional common responses included concerns about a lack of mask wearing, particularly among runners and bicyclists, and a lack of (open) public restrooms (e.g. "No open bathrooms") or concerns about the safety of using public restrooms.

Respondents with different racial and ethnic identities also reported some different concerns about visiting parks and open space (Figure 2A). Asian respondents more frequently reported concerns about social distancing, Latinx respondents more frequently selected lack of park staff, and Black respondents were more concerned about police presence (Table 1). Respondents who identify as having a nonbinary gender identity were also more concerned about police presence, as well as inadequate lighting in parks, compared to females. There were no significant differences in concerns reported by males and females.

There were also some significant differences in concerns reported across boroughs (Figure 2B). Concerns about crowded parks were lower in the Bronx and Staten Island and concerns about a lack of park staff were higher in the Bronx, compared to Manhattan (Table 1). Concerns about excessive police presence were higher in Brooklyn than in Manhattan. Additionally, access to urban green spaces was a greater concern in Brooklyn and Queens. 

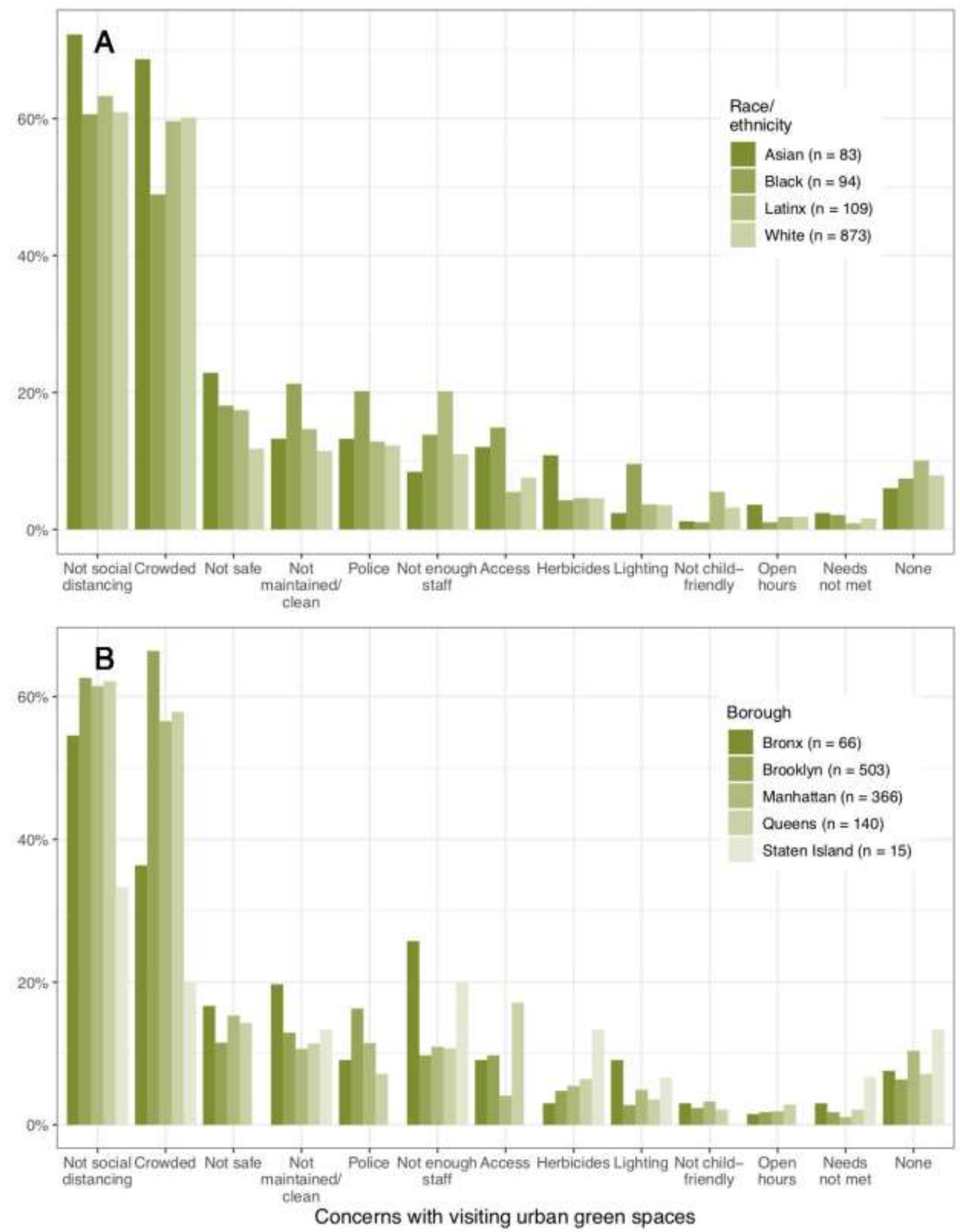
Figure 2. Variation in concerns about visiting parks and open space reported by respondents across race and ethnicity $(A)$ and NYC boroughs (B). Results of regressions testing for differences across groups can be found in Table 1.

\section{Perception of safe and easy access to urban green spaces during the pandemic}

In response to a separate question about park access, $75 \%$ of respondents said that they had "safe and easy access" to a public park and an additional $5 \%$ who did not have access to a public park had access to a natural area, beach, or NYCHA open space. White respondents had higher park access and Asian respondents had less access to beaches (Table 2). Access to a public park was highest among respondents from Staten Island (93\%) and Manhattan (83\%) and significantly lower among respondents from Brooklyn (76\%) and Queens (63\%). Access to "natural areas" was highest for respondents from the Bronx and Staten Island (both $53 \%$ of respondents) and significantly lower in Brooklyn (20\%) and Manhattan (22\%). The proportion of respondents who stated that they did not have "safe and easy access" to a public park was unrelated to the amount of green space at the zip code scale $(p=0.55)$.

Most respondents $(58 \%)$ reported traveling ten minutes or less to the park or open space they visit most often (340 traveling < 5 minutes, 327 traveling 5-10 minutes). Of the 790 respondents $(69 \%)$ who walk to the park or open space they visit most frequently, $73 \%$ walk for ten minutes or less. Travel times were longer on average for respondents who travel to their most visited park by bicycle (7\% of respondents), car or motorcycle $(6 \%)$, or train (1\%). Travel times were significantly higher for respondents living in Brooklyn and Queens, compared to Manhattan (Table 3).

\section{Park use during the pandemic}

Over $20 \%$ of survey respondents reported that they had visited a park or open space 3-4 times during the preceding week and another $20 \%$ had gone about once per day (Figure $3 \mathrm{~A}$ ). There were no differences across gender or borough in the frequency of park visits, but Latinx respondents visited parks less frequently (Table 3 ).

Only $\sim 35 \%$ of respondents chose to report how their participation in visiting parks had changed during the pandemic. Although few reported that they started visiting parks during the pandemic, $15 \%$ of respondents increased their participation in park visits (Figure 3B). About $1 \%$ of respondents (15 total) stopped visiting parks during the pandemic, and another $14 \%$ decreased their participation in visiting parks during the pandemic. There were no significant differences in the change in park visitation across gender, race/ethnicity, or borough (Table 3). Respondents were less likely to increase their park visitation during the pandemic if they reported concerns about social distancing (estimated odds ratio $=0.53$ ), access to parks and open space (estimated odds ratio $=0.30$ ), or the safety of parks and open space (estimated odds ratio $=0.33$ ). Concerns about crowded parks and park cleanliness did not predict changes in park visitation during the pandemic. However, several comments about park visitation suggest these may be key concerns among some respondents. 


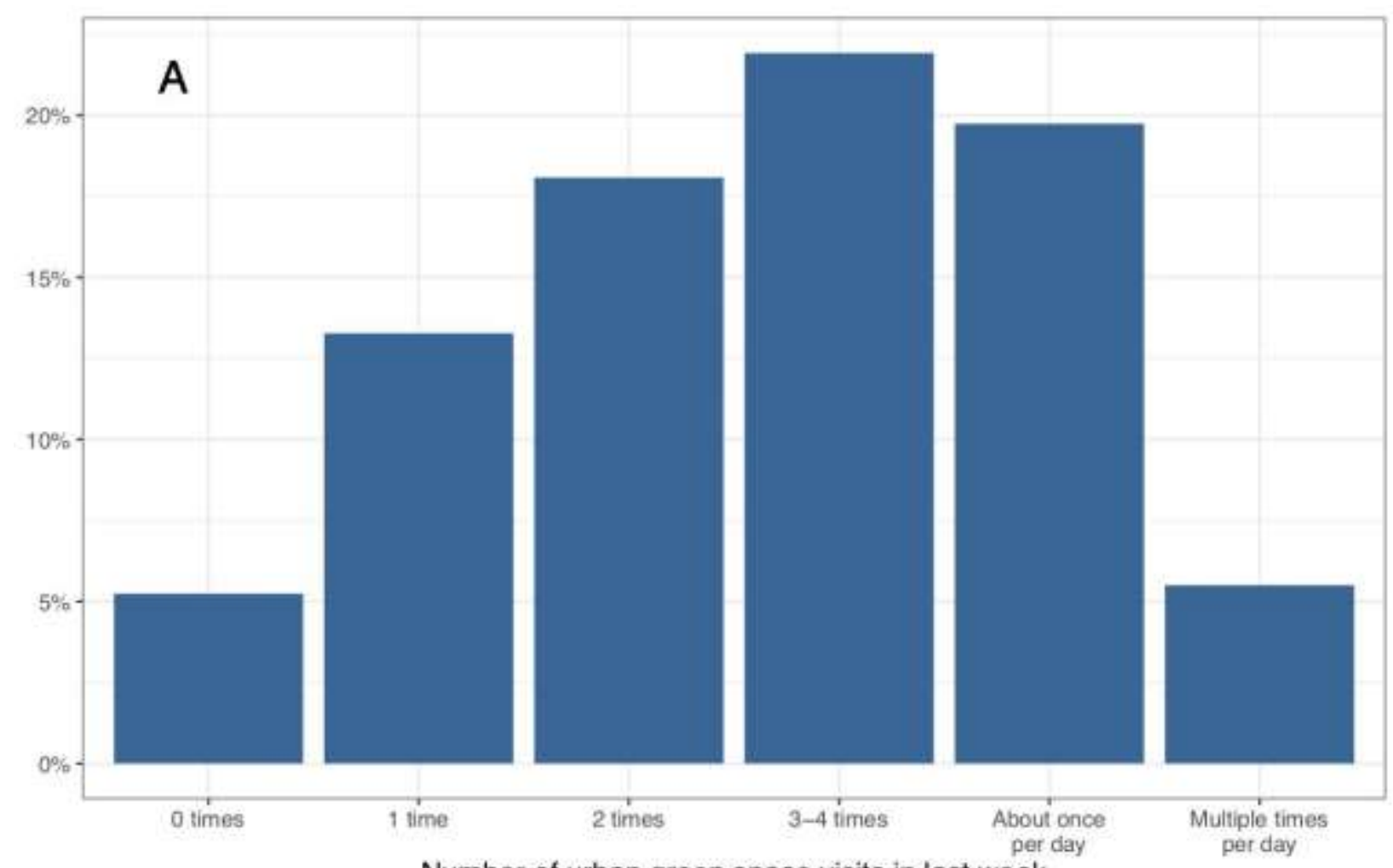

Number of urban green space visits in last week

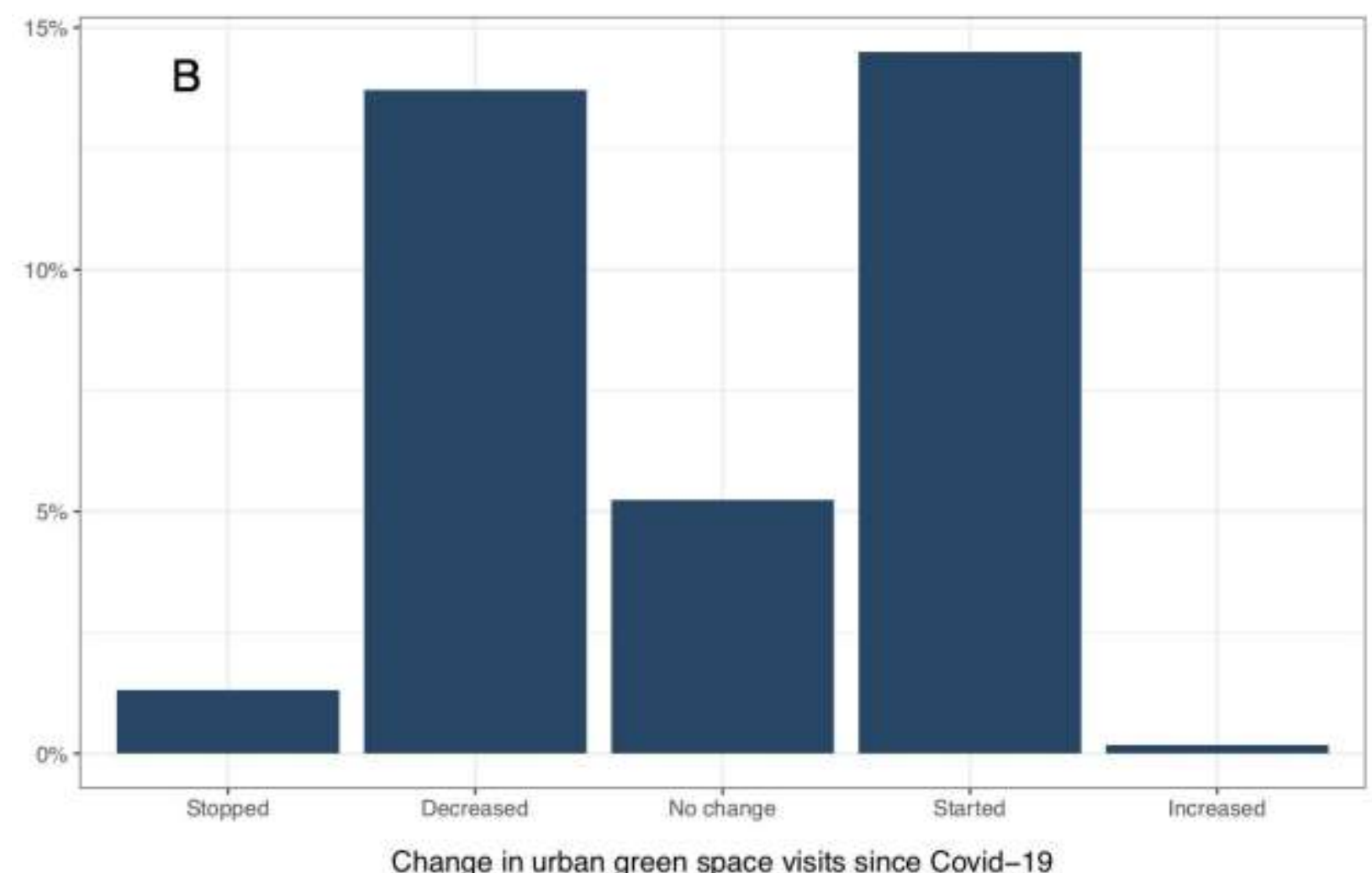


Figure 3. Distribution of responses to the questions "How many times have you visited a park or open space in the last week?" (A) and "How has your participation in [visiting parks or open space] changed since the start of the COVID-19 crisis?" (B).

\section{Importance of parks for mental and physical health}

Sixty-seven percent of respondents reported that they currently consider parks and open space to be "extremely important" for their mental health, and another $21 \%$ consider parks "very important" for their mental health (Figure 4, right-hand bars). The importance of parks for physical health was rated slightly lower overall, with 55\% considering parks "extremely important" and 25\% "very important".
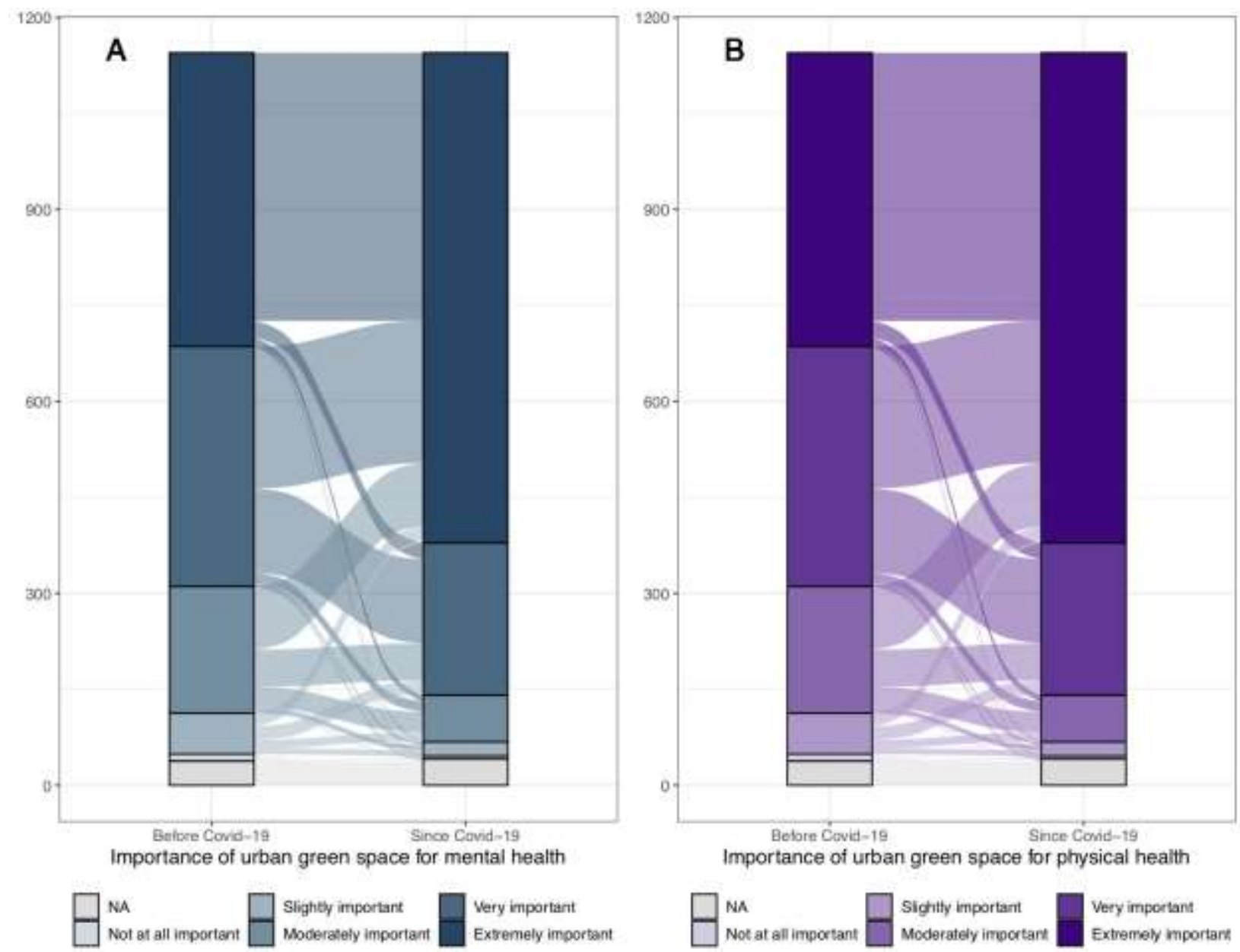

Figure 4. Perceived importance of parks and open space for mental $(A)$ and physical $(B)$ health before (left-hand bars) and during (right-hand bars) the pandemic. Shaded areas between bars are made up of lines connecting individuals' responses regarding the two time periods. Thicker shaded areas represent a larger proportion of respondents who made the same selections; for example, the largest proportion of respondents selected that parks were "Extremely important" both before and during the pandemic (darkest shaded area connecting the two top bars) for both mental and physical health. 
Results varied across gender, race, and borough (Table 3). Males ranked parks as less important for both mental and physical health than did females (Figure 5). Black respondents also ranked parks less important for mental and physical health than respondents who did not identify as Black, and Asian respondents ranked parks as less important than others for physical health only (Figure 5). Respondents from Queens ranked parks as lower for mental and physical health than respondents from Manhattan.

On average, respondents reported that they consider parks and open space slightly more important for their physical and mental health now than they did before the start of the COVID- 19 crisis. Although $51 \%$ and $52 \%$ of respondents reported no change in their assessment of park importance for mental and physical health, respectively (mostly due to respondents selecting "extremely important" for both time periods; Figure 4), 39\% ranked parks as more important for mental health now than before the pandemic and $36 \%$ ranked parks as more important for physical health now than before. The most common changes in ranking of importance for health were from "very important" to "extremely important" (19\% of respondents for mental health; $15 \%$ of respondents for physical health) and from "moderately important" to extremely important" ( $8 \%$ of respondents for mental health; $7 \%$ of respondents for physical health) (Figure 3). 

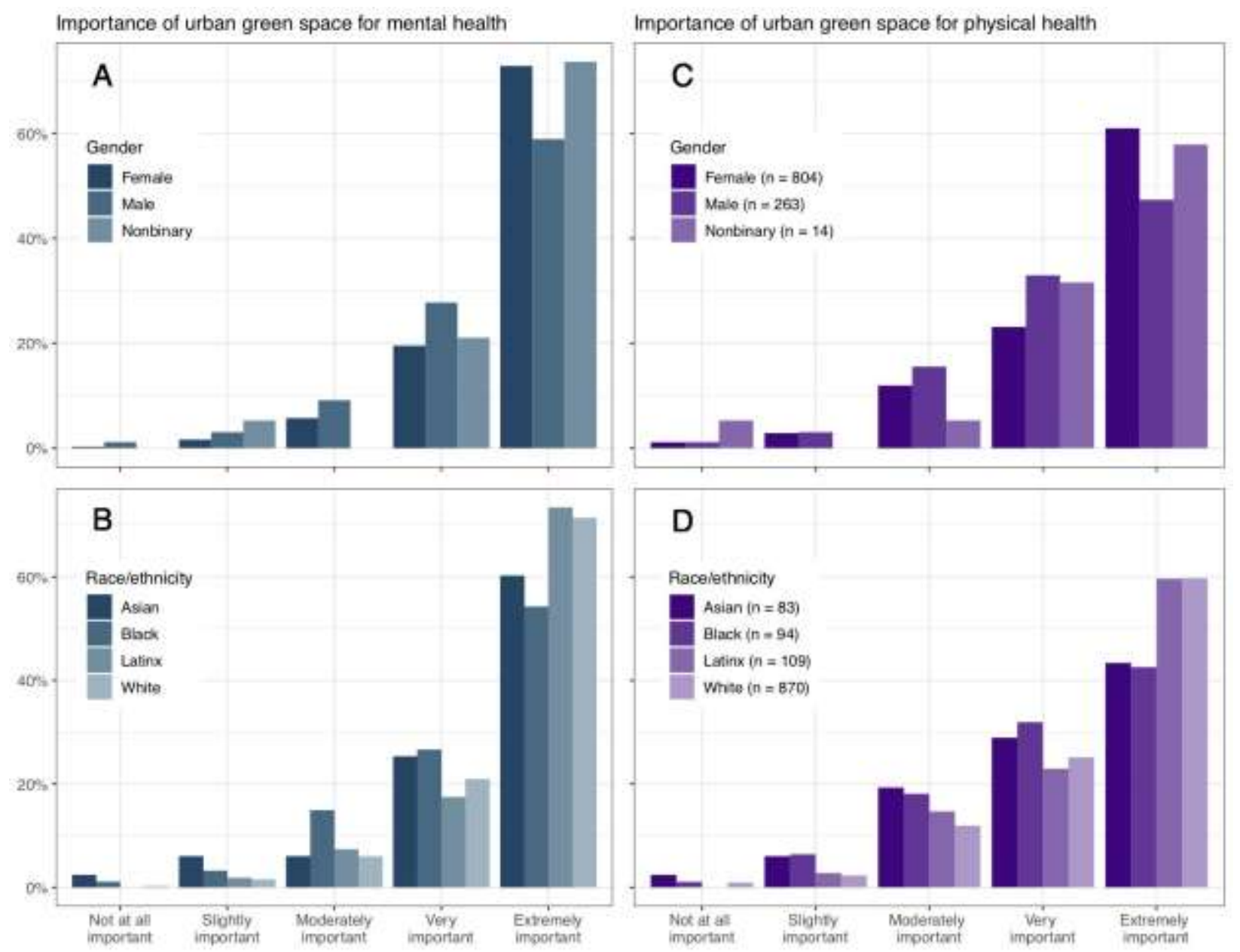

Figure 5. Variation in responses about the importance of parks and open space for mental $(A, B)$ and physical $(C, D)$ health across gender $(A, C)$ and race/ethnicity $(B, D)$ groups. Results of regressions testing for differences across groups can be found in Table

Important features of parks

Over $85 \%$ of respondents selected "Places to walk / trails" and "Trees, shade" as important features of parks, and over half of respondents selected "Places to sit" (73\%), "Landscaping / maintained gardens" (63\%), and/or "Water feature (e.g. river, lake, pond, ocean, fountain, sprinkler, pool)" (58\%).

The importance of some park features differed across gender, race/ethnicity (Figure 6), and borough. Male respondents less frequently selected trails, water features, or "Educational opportunities (e.g. informational signage, guided trails)" than female respondents and nonbinary respondents more frequently selected "Places to BBQ, cook food" than females (Table 4). Latinx respondents also more frequently selected "Places to BBQ, cook food". Black respondents less frequently selected "Opportunities to view wildlife" than others. White respondents more frequently identified "Trees, shade" as an important feature of parks and less frequently selected educational opportunities. "Landscaping / maintained gardens" was selected more frequently by respondents from Brooklyn and Queens, educational opportunities were 
more frequently selected by respondents from the Bronx, and "Trees, shade" was selected less frequently in Staten Island, as compared to Manhattan.

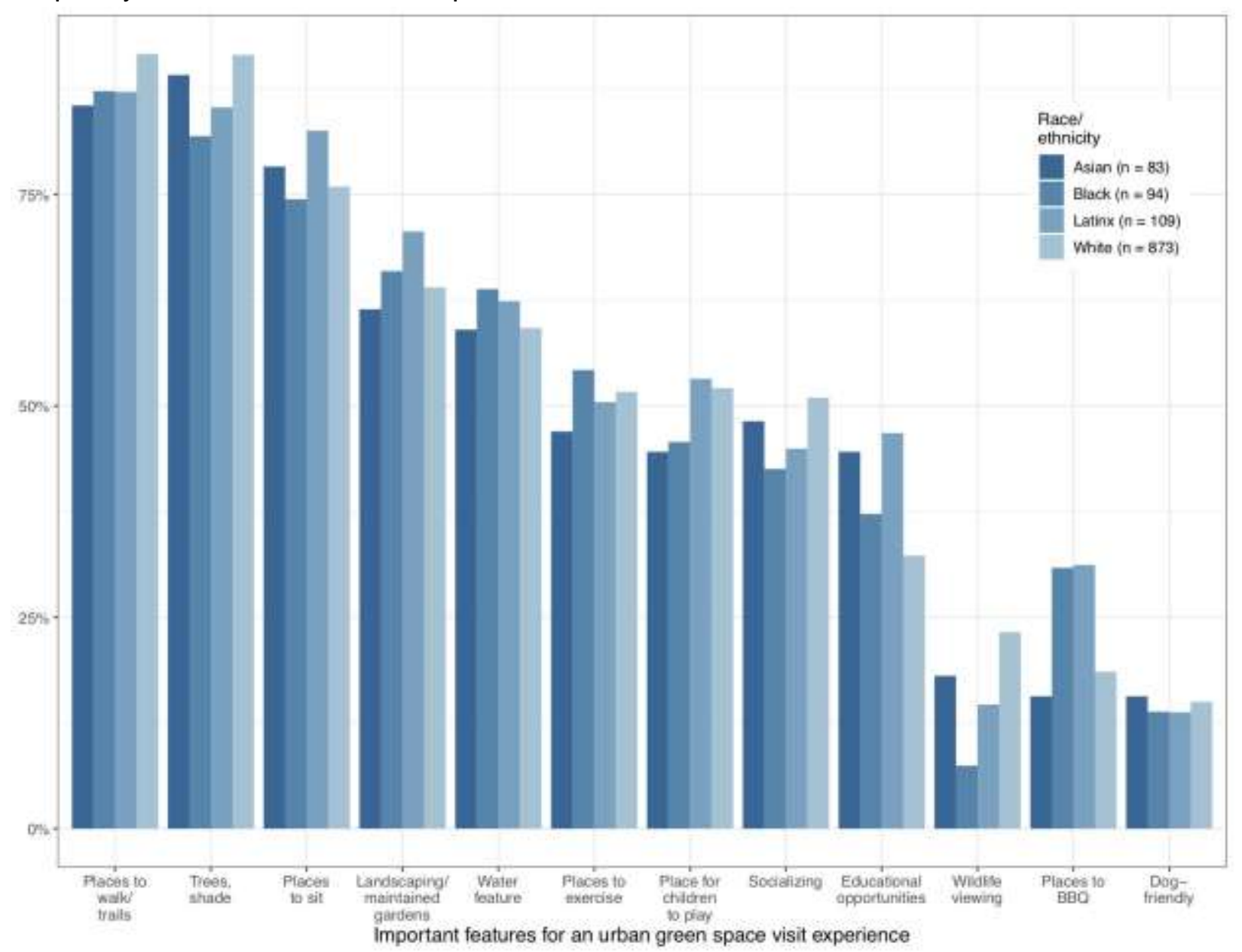

Figure 6. Variation in features considered to be important for a park or open space visit reported by respondents across race and ethnicity. Results of regressions testing for differences across groups can be found in Table 4.

On average, respondents stated that most of the features they deemed important for a park visit experience were provided by their most frequently visited park (mean $83 \pm 24 \%$, median 100\%). However, respondents from Queens reported a significantly lower proportion of the features they consider important were provided (Table 4).

\section{Discussion}

Our online survey aimed to determine how NYC residents were using urban green spaces during the early months of the COVID-19 pandemic, the perceived importance of urban green spaces during this time, and the primary green-space-related concerns and needs of residents. The results of the study provide some empirical evidence to illustrate the value of urban green spaces as critical urban infrastructure, and how the varied needs and concerns of different social groups in NYC should inform future planning and operation. Overall, we found that respondents continued to use urban green spaces during the pandemic and consider them to 
be highly important for mental and physical health, even more now than before the pandemic began. However, the study revealed a pattern of concerns residents have about green space accessibility and safety, and identified important features that allow the needs of local residents to be met. We also found key differences between the concerns and needs of different populations who took part in the survey, suggesting a crucial role for inclusive decision-making and urban ecosystem governance that reflect the differential values, needs and concerns of communities across the City (Lo and Jim 2010). The following sections provide further discussion on these differences and the implications this may have for future planning and response.

Urban green spaces are recognized as important for mental and physical health during COVID19

Urban green spaces provide a host of mental and physical health benefits (Lee, Jordan, \& Horsley, 2015). Multiple studies indicate how they promote and increase physical activity, help people recover from illness faster, improve air quality and decrease respiratory illness, in addition to improving general mental health, and reducing stress and mental disorders (Annerstedt et al., 2012). This is especially true for communities living in dense urban areas (Bateman et al., 2013; Keeler et al., 2019; Pretty et al., 2005). Through our analysis, we found that most survey participants considered urban green spaces to be very or extremely important for their health, and that this held true for all groups (across gender, race/ethnicity, and borough) analyzed in this study. This finding is likely not generalizable to all of New York City, since respondents appear to be biased in their interest in urban green spaces, with over $85 \%$ of them reporting that they visit parks. However, the overwhelming importance of urban green space in this study, and the fact that rankings of urban green space's importance increased during the pandemic, point to the necessity of providing continued access to these spaces during times of crisis to prevent further inequities in public health.

Additionally, because respondents generally considered urban green spaces to be more important for mental than physical health, this may indicate the many different roles that urban green spaces can provide for communities. In a study led by the NYC Parks and USDA Forest Service, researchers found through a Citywide Social Assessment that parks are a critical social space, and visitation correlates with park size, facilities and ability to participate in recreational activities and engagement with the local environment (Auyeung et al 2016). Others point to urban green spaces as a way to relieve the chronic stress of cramped spaces and housing, with perceived importance directly related to community quality and cohesion (Lo and Kim, 2012; Samuelsson et al 2020). These benefits may be particularly salient for cities like New York, which was hard-hit by COVID-19 during the onset of the pandemic in the US. Our survey captures a time period following some of the worst health impacts of the crisis, but before NYC entered into Phase 3 and 4, which allows for restaurants and many other businesses to partially reopen. As a documented case of ongoing "Covid depression" spreads nationwide, urban green spaces may be critical for alleviating mental stress and health (Fitzpatrick, Harris, Drawve, 2020). 


\section{Differential access to urban green spaces during COVID-19}

Overall, we found perceived access to parks is unequally distributed across the 5 boroughs, although it is relatively high given the majority of New Yorkers live within a 10-minute walk to a greenspace (Trust for Public Land 2019). Our analysis finds that Queens and Brooklyn have lower perceived park access, as well as receive less of their desired features from urban green spaces. Several studies point to neighborhoods in Queens as disproportionately impacted by COVID-19, in part because of increased social vulnerability, particularly in Western Queens (Choi 2020). This may interact with a lack of urban green space access and amenities to produce further inequities and hardships on communities already struggling with COVID-19.

Although we did not find evidence of differences in access to urban green spaces across race or ethnicity in our population sample, park use was lower for Latinx respondents, and the importance of parks for health was perceived as lower for Black respondents. Other studies have found that communities of color are more likely to lack access to green spaces of quality and to face disinvestment in local parks, which often do not include basic amenities like bathrooms or basketball courts (Neckerman 2009; Kabisch and Haase 2014; Miyake et al. 2010; Rigolon 2016). These same communities are also at higher risk and incidence to conditions such as diabetes, hypertension, exposure to extreme heat, poor air quality, and heart failure (Choi \& Unwin, 2020). These have been identified as comorbidities that significantly increase the likelihood of patients requiring hospitalization and contribute to COVID-19 fatality (Jahromi \& Hamidianjahromi, 2020).

While providing access to parks is vital, the results of our survey also indicate people may not use the park or open space closest to them if it does not have desired amenities or if it is too small and likely more crowded. These trends are supported by previous studies like the Citywide Social Assessment by NYC Parks and USDA Forest Service in 2014, which showed that park visitation correlates with park size, facilities and the ability to participate in recreational activities and engage with the local environment (Auyeung et al 2016). Several respondents shared this sentiment in a space provided for additional comments: "[The] closest park is too small to really take a walk or observe nature. Lots of paved areas and benches, with a closed playground. It's nice but a very limited amount of outdoor space. There's another park that is further away but not unreasonably far to walk that is always very crowded. A third nearby park (further than the closest but closer than the crowded one) is completely closed. Much of that park is a playground and basketball area but even the small area with benches and greenery is locked and inaccessible." Thus, maintaining important green space features during this time, as much as possible, is critical to meet residents' needs. Overall, respondents to our survey indicated that important features such as landscaping and trees, places to sit and walk, and water features were high priority. Write-in comments suggested that other urban green space features were also necessary for some respondents to meet their needs, such as public restrooms and playgrounds. These results demonstrate a tension between maintaining important features of public spaces and ensuring the safety of visitors and staff.

Although many respondents continued or even increased their visitation of urban green spaces during the pandemic, we found that concerns about safety or a lack of access to parks of quality can result in a decrease of park visits. This is attributed in part to additional safety concerns related to social distancing and overcrowding that may result in anxiety or fear in using 
urban green spaces. More than half of park users surveyed were concerned about these issues, in particular crowding and/or lack of social distancing. Increased signage and/or staff encouraging social distancing and mask wearing could help assuage some of these concerns.

\section{Assessing differential community needs is vital}

Understanding differential community needs and expectations related to urban green space use is vital during COVID-19. Our survey showed that people's views on urban green spaces vary across locations and social groups; notably, these differences were apparent despite demographic biases in the pool of respondents. For example, Black and nonbinary (gendered) respondents were more concerned about police presence in parks. In particular, respondents were concerned about racial profiling by police. One survey respondent explained: "Feels like parks for white people these days and law enforcement continue to target people of color." Although concerns about police were selected less frequently than those about more Covidspecific concerns (crowding, social distancing), the importance of these issues to particular communities demonstrates the necessity of addressing them for providing equitable urban green spaces.

Generally, differences in concerns and features deemed important for urban green spaces point to the need for including communities in decision-making around the design and management of parks. We found that different communities may place different value on park features such as wildlife habitat, educational opportunities, or places to socialize and cook food within parks. These findings are consistent with other studies, such as one focused on Chicago parks that found that Black communities were more likely to mention facilities and social activity, while White and Asian communities placed greater emphasis on natural areas or features (Gobster 2002). Our results highlight the ways in which residents' diverse beliefs and attitudes are not necessarily uniform, and point to a need for participatory planning processes and procedural justice reforms that may be especially critical as additional concerns attributed to the current pandemic are identified by park users.

\section{Urban green spaces as critical urban infrastructure during extreme events}

In times of crisis, urban green spaces increasingly emerge as more than essential, but rather critical urban infrastructure to manage the multiple impacts of COVID-19, especially for socially vulnerable communities. The Department of Homeland Security describes "critical infrastructure" as assets that have a substantial impact on public health or safety, yet seldom asks critical how and for whom. Urban green spaces are thus rarely considered "critical infrastructure" in the planning and allocation of funding in times of crisis despite being multifunctional infrastructure systems that can provide many functions and benefits at the same time (Childers et al. 2019). These spaces provide critical services such as transportation, flood protection, protection from lethal heat waves, support local and regional economic activity, and form part of the education system (Le et al. 2019; Sadeghian \& Vardanyan 2013). Currently, urban green spaces in NYC are designated as an "essential business" under New York State Executive Order 202.6. However, the operation and closure of urban green spaces are at the discretion of state and local governments based on their capacity to enforce social distancing 
and cleaning/disinfecting measures. With looming budget cuts and reduced staffing expected well into the future, a key question remains for city planners and officials on how to meet these new demands and be able to adopt and support new policies in the face of budget cuts for staff and maintenance.

This is especially crucial in considering the interdependent and cascading risks of extreme events such as heat waves and coastal storms, and how they may interact with COVID-19. A reduction in staffing at NYC Parks for instance is already having major impacts on City services in the aftermath of Tropical Storm Isaias, which hit the Northeastern seaboard in early August 2020 causing more than 800,000 to lose power in New York State. NYC Parks is the agency responsible for clearing downed trees, the cause of most of the damage, but were reportedly delayed because of budget cuts and staffing shortfalls. NOAA predicts the 2020 Atlantic Hurricane season, with 70\% probability, to include at least 19-25 more similar events this year alone.

Reframing UGS as a form of critical urban infrastructure may allow officials to think differently about not only leveraging the multiple health, social, economic and environmental benefits of these urban green spaces but also re-imaging the City's park systems as a responsive green corridor network, linking smaller parks with larger parks, waterfront hubs, open/cool streets, and natural areas to promote ecological and social connectivity. The green corridor or network concept has been documented for instance to double the likelihood of achieving 20 minutes of moderate to vigorous physical activity (Fran, Hong \& Ngo 2019), advance public transportation, and address the health impacts of extreme weather like heat waves (Shashua-Bar and Hoffman 2000; Aram et al. 2019; Brown et al 2015) often at a fraction of the economic costs of other infrastructure systems (Depietri \& McPhearson 2017). This may address some of the inequitable distribution of urban green space that have the features residents need in order to cope with the impacts of COVID-19, while also improving how residents' access these spaces, which was a concern reflected in the results of the survey. Although NYC is a specific case, we feel the findings of the study may provide additional insights for other U.S. cities weighing their own responses to the ongoing crisis and how best to support those most vulnerable to the interrelated impacts of COVID-19.

\section{Acknowledgements}

This material is based upon work supported by the National Science Foundation under Grant Number (2029918). Any opinions, findings, and conclusions or recommendations expressed in this material are those of the author(s) and do not necessarily reflect the views of the National Science Foundation. Funding for the study is also provided in part by the New York State Health Foundation, with additional support from The Nature Conservancy of New York and Building Healthy Communities NYC. Initial spatial analysis of urban green space area developed by Dr. Ahmed Mustafa at the Urban Systems Lab, The New School. Selected survey questions adapted from the work of Dr. Elizabeth Cook, Dr. Megan Maurer and Dr. Liv Yoon at Barnard College, as well as a European survey developed by Dr. Johannes Langemeyer and Dr. Francesco Baró. 


\section{References}

Heidt V, Neef M. 2008. Benefits of Urban Space for Improving Urban Climate, Ecology, Planning and Management of Urban Forests: International Perspective.

Shashua-Bar, L. and Hoffman, M. (2000) Vegetation as a Climatic Component in the Design of an Urban Street: An Empirical Model for Predicting the Cooling Effect of Urban Green Areas with Trees. Energy and Buildings, 31, 221-235.

Lee, A. C. K., Jordan, H. C., \& Horsley, J. (2015). Value of urban green spaces in promoting healthy living and wellbeing: prospects for planning. Risk Management and Healthcare Policy, 8, 131-137. https://doi.org/10.2147/RMHP.S61654

Maas J, Verheij RA, Groenewegen PP, De Vries S, Spreeuwenberg P. 2006. Green space, urbanity, and health: how strong is the relation? Journal of Epidemiology and Community Health 60, 587-592.

Bratman, G.N., Daily, G.C., Levy, B.J., and Gross, J.J. (2015). The benefits of nature experience: Improved affect and cognition. Landscape and Urban Planning 138, 41-50.

Bratman, G.N., Anderson, C.B., Berman, M.G., Cochran, B., Vries, S. de, Flanders, J., Folke, C., Frumkin, H., Gross, J.J., Hartig, T., et al. (2019). Nature and mental health: An ecosystem service perspective. Science Advances 5, eaax0903.

Brooks, S. K., Webster, R. K., Smith, L. E., Woodland, L., Wessely, S., Greenberg, N., \& Rubin, G. J. (2020). The psychological impact of quarantine and how to reduce it: rapid review of the evidence. The Lancet, 395(10227), 912-920. https://doi.org/10.1016/S01406736(20)30460-8

Rigolon, A. (2016). A complex landscape of inequity in access to urban parks: A literature review. Landscape and Urban Planning, 153, 160-169.

https://doi.org/10.1016/j.landurbplan.2016.05.017

Weiss, C. C., Purciel, M., Bader, M., Quinn, J. W., Lovasi, G., Neckerman, K. M., \& Rundle, A. G. (2011). Reconsidering access: park facilities and neighborhood disamenities in New York City. Journal of Urban Health: Bulletin of the New York Academy of Medicine, 88(2), 297-310. https://doi.org/10.1007/s11524-011-9551-z

Miyake, K., Maroko, A., Grady, K., Maantay, J., \& Arno, P. (2011). Not Just A Walk in The Park: methodological improvements for determining environmental justice implications of park access in New York City for the promotion of physical activity. Cities and the Environment (CATE), 3(1). https://digitalcommons.Imu.edu/cate/vol3/iss1/8

Auyeung, D. S. N., Campbell, L. K., Johnson, M., Sonti, N. F., \& Svendsen, E. (2016). Reading the landscape: citywide social assessment of New York City parks and natural areas in 2013-2014. Social Assessment White Paper No. 2. New York, NY: New York Department of Parks and Recreation. 69 P., 1-69

Lo, A. Y. H., \& Jim C.Y. 2012. Citizen attitude and expectation towards greenspace provision in compact urban milieu Land Use Policy, 29 (3) (2012), pp. 577-586, 10.1016/j.landusepol.2011.09.011

Hamstead, Z. A., Fisher, D., Ilieva, R. T., Wood, S. A., McPhearson, T., \& Kremer, P. (2018). Geolocated social media as a rapid indicator of park visitation and equitable park access. Computers, Environment and Urban Systems, 72, 38-50.

https://doi.org/10.1016/j.compenvurbsys.2018.01.007 
Fisher, B., \& Grima, N. (2020). The importance of urban natural areas and urban ecosystem services during the COVID-19 pandemic. https://doi.org/10.31235/osf.io/sd3h6

Venter, Z., Barton, D., Gundersen, Vegard, Figari, H., \& Nowell, M. (2020). Urban nature in a time of crisis: recreational use of green space increases during the COVID-19 outbreak in Oslo, Norway. https://doi.org/10.31235/osf.io/kbdum

Samuelsson, K., Barthel, S., Colding, J., Macassa, G., \& Giusti, M. (2020). Urban nature as a source of resilience during social distancing amidst the coronavirus pandemic. OSF Preprints. https://ideas.repec.org/p/osf/osfxxx/3wx5a.html Goldstein, J., \& Kilgannon, C. (2020, May 2). Balmy Weekend Presents a Challenge: New Yorkers Rushing to Parks. The New York Times. https://www.nytimes.com/2020/05/02/nyregion/weather-parks-nyc-nj-coronavirus.html

Melendez, S. (2020, April 3). Report: Parks in some states saw a huge increase in foot traffic despite the COVID-19 pandemic. Fast Company. https://www.fastcompany.com/90486326/report-parks-in-some-states-saw-a-hugeincrease-in-foot-traffic-despite-the-covid-19-pandemic

U.S. Census Bureau. 2018 American Community Survey 1-Year Estimates. https://data.census.gov/cedsci/ (13 August 2020).

New York City Department of Parks and Recreation. (2020). Frequently Asked Questions : NYC Parks. https://www.nycgovparks.org/about/faq

Harnik, P., Martin, A., \& Treat, M. (2016). 2016 City Park Facts. Trust for Public Land. https://www.tpl.org/sites/default/files/2016\%20City\%20Park\%20Facts 0.pdf

New York State Department of Health and Mental Hygiene. New York State on PAUSE. Department of Health (July 17, 2020).

Venables, W. N. \& Ripley, B. D. (2002) Modern Applied Statistics with S. Fourth Edition. Springer, New York. ISBN 0-387-95457-0

R Core Team (2019). R: A language and environment for statistical computing. $R$ Foundation for Statistical Computing, Vienna, Austria. URL https://www.R-project.org/.

Angel, M. M. S. Tamayo, P. Lamson-Hall, \& A. Blei, "The Coronavirus and the Cities: Explaining Variations in U.S. Metropolitan Areas as of 27 March 2020” (2020) (June 22, 2020).

White, Matthew, lan Alcock, Benedict Wheeler, and Michael Depledge. 2013. Would You be Happier Living in aGreener Urban Area? A Fixed-Effects Analysis of Panel Data. Psychological Science 24: 920-28.

Lo, A. Y. H., \& Jim, C. Y. (2010). Differential community effects on perception and use of urban greenspaces. Cities, 27(6), 430-442. https://doi.org/10.1016/j.cities.2010.07.001

Annerstedt M, Ostergren PO, Bjork J, Grahn P, Skarback E, Wahrborg P. 2012. Green qualities in the neighbourhood and mental health results from a longitudinal cohort study in Southern Sweden. BMC Public Health 12, 337.

Bateman, I.J., Harwood, A.R., Mace, G.M., Watson, R.T., Abson, D.J., Andrews, B., Binner, A., Crowe, A., Day, B.H., Dugdale, S., Fezzi, C., Foden, J., Hadley, D., Haines-Young, R., Hulme, M., Kontoleon, A., Lovett, A.A., Munday, P., Pascual, U., Paterson, J., Perino, G., Sen, A., Siriwardena, G., Soest, D. van, Termansen, M., 2013. Bringing Ecosystem Services into Economic Decision-Making: Land Use in the United Kingdom. Science 341, 45-50. https://doi.org/10.1126/science.1234379 
Keeler, B.L., Hamel, P., McPhearson, T., Hamann, M.H., Donahue, M.L., Meza Prado, K.A., Arkema, K.K., Bratman, G.N., Brauman, K.A., Finlay, J.C., Guerry, A.D., Hobbie, S.E., Johnson, J.A., MacDonald, G.K., McDonald, R.I., Neverisky, N., Wood, S.A., 2019. Social-ecological and technological factors moderate the value of urban nature. Nat. Sustain. 2, 29-38. https://doi.org/10.1038/s41893-018-0202-1

Pretty, P.J., Peacock, J., Sellens, M., Griffin, M., 2005. The mental and physical health outcomes of green exercise. Int. J. Environ. Health Res. 15, 319-337. https://doi.org/10.1080/09603120500155963

Fitzpatrick, K. M., Drawve, G., \& Harris, C. (2020). Facing New Fears During the COVID-19 Pandemic: The State of America's Mental Health. Journal of Anxiety Disorders, 102291. https://doi.org/10.1016/i.janxdis.2020.102291

The Trust for Public Land. (2019). The Trust for Public Land 2019 ParkScore index. The Trust for Public Land. Retrieved August 21, 2020, from https://www.tpl.org/city/new-york-newyork

Choi, A. (2020, April 2). Queens Neighborhoods Hardest Hit by Virus Home to Many Service Workers. THE CITY. https://www.thecity.nyc/2020/4/2/21210380/queensneighborhoods-hardest-hit-by-virus-home-to-many-service-workers

Neckerman, K. M., Lovasi, G. S., Davies, S., Purciel, M., Quinn, J., Feder, E., Raghunath, N., Wasserman, B., \& Rundle, A. (2009). Disparities in urban neighborhood conditions: evidence from GIS measures and field observation in New York City. Journal of Public Health Policy, 30 Suppl 1, S264-285. https://doi.org/10.1057/jphp.2008.47

Kabisch, N., and D. Haase. 2014. Green justice or just green? Provision of urban green spaces in Berlin, Germany. Landscape and Urban Planning 122:129-139.

Choi, Y., \& Unwin, J. (2020). Racial Impact on Infections and Deaths due to COVID-19 in New York City. ArXiv:2007.04743 [Physics, q-Bio, Stat]. http://arxiv.org/abs/2007.04743

Jahromi, A., \& Hamidianjahromi, A. (2020). Why African Americans Are a Potential Target for COVID-19 Infection in the United States. Journal of Medical Internet Research, 22(6). https://doi.org/10.2196/19934

Gobster, P. H. (2002). Managing urban parks for a racially and ethnically diverse clientele. Leisure Sciences. Volume 24. 2002. Pp. 143-159, 24. https://www.fs.usda.gov/treesearch/pubs/12479

Childers, D. L., Bois, P., Hartnett, H. E., McPhearson, T., Metson, G. S., \& Sanchez, C. A. (2019). Urban Ecological Infrastructure: An inclusive concept for the non-built urban environment. Elem Sci Anth, 7(1), 46. https://doi.org/10.1525/elementa.385

Le, T. Q., Devisch, O., \& Trinh, T. A. (2019). Flood-resilient urban parks: Toward a framework. Area, 51(4), 804-815. https://doi.org/10.1111/area.12543

Sadeghian, M. M., \& Vardanyan, Z. (2013). The Benefits of Urban Parks , a Review of Urban Research. Journal of Novel Applied Sciences, 2(8), 231-237.

Aram, F., Solgi, E., \& Holden, G. (2019). The role of green spaces in increasing social interactions in neighborhoods with periodic markets. Habitat International, 84, 24-32. https://doi.org/10.1016/i.habitatint.2018.12.004

Brown, R. D., Vanos, J., Kenny, N., \& Lenzholzer, S. (2015). Designing urban parks that ameliorate the effects of climate change. Landscape and Urban Planning, 138, 118-131. https://doi.org/10.1016/j.landurbplan.2015.02.006 
Depietri, Y., \& McPhearson, T. (2017). Integrating the Grey, Green, and Blue in Cities: NatureBased Solutions for Climate Change Adaptation and Risk Reduction. In N. Kabisch, H. Korn, J. Stadler, \& A. Bonn (Eds.), Nature-Based Solutions to Climate Change Adaptation in Urban Areas: Linkages between Science, Policy and Practice (pp. 91109). Springer International Publishing. https://doi.org/10.1007/978-3-319-56091-5 6 